\title{
Development of Athletic Injury Psychological Acceptance Scale
}

\author{
TOMONORI TATSUMi, MS ${ }^{1)}$ \\ 1) Department of Modern Education, Faculty of Education, Kio University: 4-2-2 Umami-naka, \\ Koryo-cho, Kitakatsuragi-gun, Nara 635-0832, Japan. TEL: +81 745-54-1601, \\ FAX: $+81745-54-1600$
}

\begin{abstract}
Purpose] The world of competitive sports has its own unique subculture which at times works towards covering up psychological problems faced by athletes with injuries. The purpose of this study was to develop an "Athletic Injury Psychological Acceptance Scale (AIPAS)" to screen athletes for serious psychological problems resulting from injury. [Subjects] A total of 189 subjects responded to the survey, of which 168 (mean age= 19.93 years; average number of days unable to participate in sports $=71.84$ days, $\mathrm{SD}=88.01$ days) valid responses were subjected to analysis. [Methods] A provisional version of the AIPAS was created from question items based on face-to-face subject interviews and content validity testing by specialists. In order to test criterion-related validity of the AIPAS, subjects were asked to complete indices that would serve as an external criterion. For this purpose, indices that measure athletic rehabilitation dedication and time perspective were designed. [Results] Item analysis of the provisional AIPAS was conducted to confirm the discrimination of each item. Exploratory factor analysis identified "Self-motivation" and "Focus on the Present" as two factors of the provisional scale. Confirmatory factor analysis supported these results. The Cronbach's alpha was used to measure the internal consistency. Since $\alpha=0.81$, the reliability of the scale was confirmed. A significant correlation was found between AIPAS and external indices, indicating criterion-related validity. [Conclusion] AIPAS is a reliable and valid scale composed of two subscales. Key words: Athletic injury psychological acceptance scale (AIPAS), Psychometric properties, Injured athletes
\end{abstract}

(This article was submitted Nov. 22, 2012, and was accepted Dec. 18, 2012)

\section{INTRODUCTION}

Athletes' injuries have effects on central and peripheral levels creating problems concerning motor skill and physical strength. However, injuries also have an effect on a psychosocial level such as doubts concerning continuing with the sport or possible loss of future roles and team position. The world of competitive sports has its own unique subculture $^{1)}$. On the one hand, emotional control is considered an art-form ${ }^{2)}$, while on the other hand there is a pervasive attitude or belief that enduring through injury and pain is normal ${ }^{3-5)}$. This type of environment makes it difficult to screen athletes with serious psychological problems, epitomized by Tsuburaya's suicide ${ }^{6}$. There is an unmet need for an index that can objectively rate the psychological recovery of injured athletes.

In previous studies, scales that measure general mood or individual emotional states of injured athletes have been used such as POMS (Profile of Mood State) ${ }^{7-9)}$, SFAIQ (Sportsmen's Feeling After Injury Questionnaire) $)^{9)}$, or ERPFI (Emotional Recovering Process from Injury Scale). However, these scales are created to measure the emotional response or changes in response following a sports injury. They do not provide a reliable index for the need for psychological intervention and do not serve as an index

E-mail: t.tatsumi@kio.ac.jp for recovery. These emotion scales are useful for predicting the cognitive and behavioral level responses of athletes with injuries, but cannot predict the factors that are causing the behavioral responses. An injury suffered by an athlete is construed as an experience characterized by object loss or psychological trauma in the field of psychoanalysis. Regarding this point, it seems possible that indices such as MTRR (multidimensional Trauma Recovery and Resilience measures) ${ }^{10)}$ or PTGI (Post Traumatic Growth Inventory) ${ }^{11)}$, which measure recovery or growth following psychological trauma may be utilized. For example, the eight psychological functions that compose the MTRR (Authority over memory, Integration of memory and affect, Affect tolerance and regulation, Symptom mastery and positive coping, Self-esteem, Self-cohesion, Safe attachment, Meaning) ${ }^{10)}$ or the two factors that comprise the PTGI (Relating to others, New Possibilities, Personal strength, Spiritual change, and Appreciation of life) ${ }^{11)}$ could also be used to measure the psychological recovery of injured athletes. Although these scales were created from a diagnostic perspective for psychological recovery, they do not predict the factors that affect the psychological recovery process. Therefore the above scales may be effective at predicting the state of psychological recovery, but do not provide insight from the perspective of psychological intervention. In order to create a scale that measures the state of psychological recovery for injured athletes, it is necessary to identify the factors that affect the recovery process from the perspective of psycho- 
logical intervention. We believe that the theory of injury acceptance is able to address both issues. In addition, promoting injury acceptance would foster emotional adjustments and active behavioral changes towards recovery ${ }^{8,12-18)}$.

It is not a simple task for an injured athlete to openly accept the injury and begin the road to recovery. For athletes that depend on competitive sports to confirm their own identity, the psychological process following injury is filled with grief and is characterized by ego defense mechanisms ${ }^{15}$. For as long as these injured athletes are consumed with their injured bodies and the negative psychosocial effects from physical injury, we cannot expect them to actively pursue athletic rehabilitation ${ }^{15,19)}$. What makes rehabilitation possible is the release of emotional grief by the injured athlete and control over their own emotions which enables acknowledgement of the seriousness of the injury and limitations resulting from the injury ${ }^{7,8)}$. The ability to accept injury creates the proper mindset ${ }^{16)}$ to choose between effective forms of treatment ${ }^{14,16)}$. In this study, we posit that the nature of injury acceptance is indicative of psychological recovery and can be predictive from the perspective of psychological intervention.

The history of rehabilitation psychology has pointed out the importance of a holistic approach and the necessity to incorporate the psychosocial perspective. Theories postulated by the psychodynamic perspective or behavior theory perspective have had a great impact on the domain of athlete rehabilitation for injured athletes. The perspective of injury acceptance in the prediction of intervention is based upon elements of psychodynamic theory. The specifics of the concept of injury acceptance are clarified by organizing the main ideas presented by psychodynamic theory regarding athletic rehabilitation and working out practical issues.

The psychodynamic perspective focuses on the recovery of the ego of injured athletes in the context of the mourning component in psychoanalysis. The Acceptance in Physical Rehabilitation Theory put forth by the psychotherapist Grayson $^{20)}$ and the Adjustment to Misfortune Theory by Dembo-Wright ${ }^{21,22)}$ are representative theories of athletic rehabilitation. Four factors of Wright's Adjustment to Misfortune Theory, "Enlargement of Scope of Values," "Subordinating physique," "Transforming Comparative Values into Asset Values," and "Containing disability effects" have been applied to the testing of "Psychological Acceptance of Injury" among injured athletes ${ }^{23}$. However, these theories are based on the assumption that the suffered injury is incurable in nature and focus mainly on psychosocial aspects and physical adaptations. Thus, it is possible that these theories do not encompass injured athletes with hope for recovery. Also, Dembo-Wright's ${ }^{21}{ }^{22}$ ) findings may be confounded by the subjects' participation in the research study ${ }^{24)}$. The interpretation of the findings requires caution because the changes may have been elicited from merely by participation in the research study. The study was conducted on subjects facing the reality of giving up on recovery, but also aware of the fact that they needed to alter their set of values in order to support their own ego. It is likely that these results are not indicative of subjects with injuries that are still in the acute phase. Inappropriate psychological in- tervention based on these findings may become a source of unwanted pressure or stress. It is also possible that there are differences in acceptance and value systems regarding rehabilitation between subjects with physical disabilities and those with physical injuries. For injured athletes, in addition to the direct effects of injury, the effects of diminished athletic performance and psychosocial effects (grief $)^{25}$ must also be considered. In short, the creation of a specialized acceptance scale for injured athletes is needed.

Taking these points into account, Tatsumi et al. ${ }^{14)}$ aimed to create an injury acceptance scale that encompasses the many effects of injury. First, injury case studies were examined, followed by creating a definition of injury acceptance among athletes, then the predictive factors of injury acceptance were clarified. Injury acceptance was defined as "The psychological state in which an injured athlete is aware of the difficulties of injury but can control his emotions to actively figure out what needs to be done immediately, and what needs to be done with priority in order to overcome the injury. Four dimensions that are predictive of injury acceptance were identified: "emotional stability," "time perspective," "sense of unity with the team," and "detachment coping." Among these four factors, "detachment coping" seems to be the most related to the acceptance state. Following injury, athletes are often faced with negative emotions such as shock and uncertainty. However, when these negative emotions are released, the injured athlete becomes more emotionally stable ${ }^{7,8,14)}$. A large part of the negative emotions that are released are reflective of the wavering ego identity, being lost, and losing the future vision (outlook). This loss of identity also may make situations more likely where the injured athlete loses rapport with interpersonal relationships ${ }^{13,14)}$. The emotional state, time perspective, and sense of unity with the team provide predictive clues towards injury acceptance ${ }^{14)}$. These three factors seem to be closely related with the awareness and detachment from the negative effects of the injury in the present and future. Similarly, these factors seem closely related to the level of detachment from the occurrence of the injury and thoughts about the healthy past prior to the injury. "Detachment coping" fosters the release from negative thoughts and indicates that a person is "Emotionally coming to terms with the injury situation" and is "Focusing on rebuilding a new lifestyle"15). "Emotionally coming to terms with the injury situation" indicates a psychological state in which the injured person accepts all the negative effects and possible ripple effects of the injury and realizes that the reality of the injury is inevitable. On the other hand, "Focusing on rebuilding a new lifestyle" indicates the acceptance of the reality of the injury as well a shift in focus towards the future in rebuilding a new self and lifestyle.

Theories that incorporate "detachment coping" include the "Giving Up-Given Up" complex proposed by Schmale et al. ${ }^{26)}$ and Engel et al. ${ }^{27)}$. According to their theory, people are torn between two conflicting emotions when they encounter loss. One emotion is the inability to give up on the loss, while the other accepts the loss as reality. This conflict brings about grief. As time passes, the conflict weakens and enables the individual to give up and accept the loss. 
"Emotionally coming to terms with the injury situation" and "Focusing on rebuilding a new lifestyle" may be emotional states that arise during similar stages. We believe that "Emotionally coming to terms with the injury situation" enables the injured person to be able to choose coping options during the stages of athletic rehabilitation or recovery. "Focusing on rebuilding a new lifestyle" likely presents itself later in the process and becomes evident in the active coping strategies on a behavioral level. Uemukai ${ }^{7)}$ has focused on impatience as an emotion unique to injured athletes. During athletic rehabilitation, one of the problems that are encountered is overwork by injured athletes especially during the early stages of rehabilitation which inevitably may lead to re-injury. Impatience may be closely tied to this problem. Injured athletes who face this problem may not have been fully successful in "Emotionally coming to terms with the injury situation" and are unable to make rational choices in coping. Therefore, it is important to consider the two aforementioned emotional states when guiding an injured athlete towards a stable rehabilitation program.

Taking this into account, we created a sports injury acceptance survey from the two factors that make up detachment coping cited in previous studies ${ }^{14,15)}$. The survey was tested for reliability and validity.

\section{SUBJECTS AND METHODS}

\section{Subjects}

Since it can be predicted that the degree of injury or the level of dedication towards sports can affect the psychological effects of injury, the subjects were recruited based on the following criteria.

(a) Injured athletes who were required to refrain from athletic activities for at least one week and were participating in athletic rehabilitation.

(b) Injured athletes who were no longer required to refrain from athletic activities, but were still continuing athletic rehabilitation.

(c) Injured university athletes belonging to the physical education department who were inclined for athletics and had a relatively long athletic career.

Subjects of this study fulfilled either criteria a and c, or $\mathrm{b}$ and $\mathrm{c}$. These qualifying standards have also been used in previous studies $7,19,28-30$ ). First, the objectives of this study were explained to the sports psychologist, team coach, team manager, or doctor at five universities in Japan with a physical education/athletics department. They were asked to be in charge of distributing and collecting the surveys as well as providing consent for participation in the study. Injured athletes who were asked to participate in the survey were asked for their consent to cooperate with the research study. A total of 189 injured athletes agreed to participate in this study. This study was approved by the Kio University Research Ethics Committee.

\section{Methods}

Described below are the compilation and organization of question items for the Athletic Injury Psychological Acceptance Scale (AIPAS), the methods used to test for reliability and validity, the external indices utilized, the methods used to carry out the study, and the methods used for analysis.

Before compiling the question items for the AIPAS, the nature of injury acceptance among athletes was studied in previous studies. ${ }^{14,15,28-30)}$ We attempted to understand injury acceptance from the perspective of "detachment coping." "Detachment coping" is divided into "Emotionally coming to terms with the injury situation" and "Focusing on rebuilding a new lifestyle" following a sports injury.

In order to design AIPAS question items, semi-structured interviews were conducted with five former university athletes who suffered injuries that forced them to be sidelined and undertake athletic rehabilitation. The interviews were retrospective and conducted in three sessions lasting approximately 60 to 80 minutes each. In order to foster discussion on specific experiences, the interviewees were asked about four points: emotional states, interpersonal relationships within the team, coping strategies with the injury, and effort towards rehabilitation. The interviews were recorded with consent of the interviewees. Question items of the scale were created based on these interview records to fit the two factors that make up the scale. In order to limit the psychological burden on the injured athletes, we aimed to make a survey with fewer than 10 question items. The created survey consisted of seven total question items: four question items dealing with "Emotionally coming to terms with the injury situation," and three question items dealing with "Focusing on rebuilding a new lifestyle." Following a revision process conducted with the clinical psychologist in charge of sports psychology at the graduate school and counseling theory to edit the content validity of the question items, all question items were retained. Furthermore, the content validity of the question items were also checked by two certified physical therapists specialized in sports medicine. Both therapists confirmed the content validity of all of the question items. The provisional AIPAS (7 question items/ 7-point Likert scale) was created following this process. Survey subjects responded by choosing from 7-point Likert scale (1: not at all $\sim$ : very much).

The correlation of the AIPAS with two external indices was conducted to test the criterion-related validity of the scale. One index was the Athletic Rehabilitation Dedication Scale (ARDS) which is used to measure the level of dedication of athletes during rehabilitation. The validity of this scale was confirmed by us in prior studies ${ }^{15}, 19,30$ ). This scale is based on Brewer's Sports Injury Rehabilitation Scale (SIRAS) ${ }^{31)}$ and comprises three items (Participation: "I always participate in scheduled rehabilitation sessions unless there is a reason." Completion: "I complete the scheduled athletic rehabilitation program for each session." Effort: "I give my best effort during athletic rehabilitation assignments."). These three items were adapted by Fisher et al. ${ }^{32)}$, Duda et al. ${ }^{33)}$, Lampton et al. ${ }^{34)}$ and Daly et al. ${ }^{35)}$ from a third-person rating scale to a self-rating scale for Rehabilitation Adherence. Previous studies have found a positive correlation between injury acceptance and athletic rehabilitation dedication $7,8,13-17,19,29,30)$, enabling us to use this scale as an external index to test the validity of the AIPAS. The response format for the ARDS was altered 
to the 7-point Likert scale (1: not at all 7: very much) and the correlation between the ARDS and AIPAS was calculated. A positive correlation would be an indicator of validity. The other scale utilized was the Time Perspective Scale (TPS) which measures the acquisition of time perspective. This scale was used in our prior study ${ }^{30)}$ and is comprised of three question items: "Outlook on life during athletic rehabilitation," "Outlook on making the scheduled return date," and "Outlook on life after returning to the sport." The reason behind using this scale as an external index is that Nakagomi et al. ${ }^{13)}$ and Tatsumi et al. ${ }^{14)}$ have demonstrated that future perspective is one of the problems faced by injured athletes. Katsumata ${ }^{36)}$ has demonstrated that psychologically healthy individuals prioritize the future and many studies ${ }^{37-39)}$ of adolescents support the notion of promoting the acquisition of future perspective. These findings support the use of the TPS as an external index to test the validity of the AIPAS. We believe that time perspective can be used to predict the outlook of injured athletes on life during athletic rehabilitation, on making the scheduled return date, and life after returning to the sport. The question item for the outlook on life during athletic rehabilitation was revised to "How specifically can you explain your lifestyle plans leading up to your return (participation in full practice)?" The question item for the outlook on making a scheduled return date was revised to "How likely is it that you will make your scheduled return date?" The question item for the outlook on life after returning to the sport was revised to "How specifically can you explain your future plans after your return?" The responses to the TPS were scored on an 11-point Likert scale (0: 0\% 10: 100\%). A positive correlation with the AIPAS would indicate validity. In addition, subjects were asked to answer basic questions about themselves including athletic history, past injuries, sport, past success, injury date, name of injury, and severity of injury (number of days refraining from the sport based on a doctor's opinion).

The study made use of an anonymous survey with the survey distributed inside a sealed envelope. Subjects who provided consent opened the envelopes themselves and completed the surveys. Whether or not the participant completed the survey, the survey was placed back in the envelope and sealed before submitting the response. A number of subjects were not required to respond to the TPS, thus the number of subjects for that scale is different.

The scores of the provisional AIPAS were calculated and checked for ceiling or floor effect. Discriminatory question items were identified by conducting G-P analysis and I-T correlation analysis for each question item. Exploratory factor analysis was conducted on the question items to identify factors and unnecessary question items. The content validity was also examined. The reliability was measured by calculating $\alpha$ coefficients using Cronbach's equation for internal consistency. The goodness of fit as measured by confirmatory factor analysis was determined for the model obtained by factor analysis modeling. The Goodness of Fit Index (GFI),Adjusted Goodness of Fit Index (AGFI),Comparative Fit Index (CFI) and Root Mean Square Error of Approximation (RMSEA) were utilized as indices for goodness of fit. Next, the AIPAS criterion-related validity was tested using the following procedure. The overall scores and subscale scores of the AIPAS, ARDS, and TPS were calculated and divided by the number of question items. The raw data scores from the "participation," "completion" and "effort" factors from the ARDS and "Outlook on life during athletic rehabilitation," "Outlook on making the scheduled return date," and "Outlook on life after returning to the sport" factors from the TPS were used directly. The Pearson product-moment correlation coefficient was calculated for the AIPAS overall scores and subscale scores with the overall scores and item scores of ARDS and TPS to test for criterion-related validity. The IBM SPSS 20.0 Statistics and Amos 20.0 was used for statistical analysis with the rejection of the null hypothesis set at $\alpha<0.01$.

\section{RESULTS}

A total of 168 (Age: $\mathrm{M}=19.93, \mathrm{SD}=1.06$ ) valid responses for the provisional AIPAS were subjected to analysis. Ten respondents did not clearly indicate the number of days that the injury prevented them from participating in sports. However, they were included in the analysis because it was clear from the nature of their injury that these respondents were injured for more than one week. Excluding the aforementioned respondents, the mean number of days that the injury prevented participation in sports was 71.84 days $(\mathrm{SD}=88.01)$. At the time of the survey, the injured athletes were at different stages of the recovery process. Some had just incurred the injury while others were close to recovery and participation in team practices. We concluded that the subjects were spread across different stages of the recovery process.

The question item scores from the provisional AIPAS are displayed on the left side of Table 1 . The results of Table 1 display no ceiling or floor effect. In order to test the validity of the question items, I-T correlation analysis and G-P analysis were conducted. For the I-T correlation analysis, the total scores for each of the seven question items were tallied, and the correlation coefficients between question items were calculated. The results are displayed in the center of Table 1. Between all question items, there were significant correlations with $\mathrm{r}=0.55 \sim 0.79(\mathrm{p}<0.01)$. For the G-P analysis, the total scores for each individual were tallied and the average scores for each question item were compared between subjects in the Good-group (43 subjects) and Poor-group (42 subjects). The results of independent t-test are displayed on the right side of Table 1 . A value of $p<0.01$ was computed, indicating that the seven question items are valid for the AIPAS.

Next, exploratory factor analysis (principal factor method, promax rotation) was conducted on the seven question items to clarify the factor structure. The criteria for the factors were based on Kaiser-Guttman rules. Selected factors had an eigenvalue above 1.0, an absolute value of the factor loading above 0.40 , high degree of commonality, and appropriate contents that fit the factor name.

Two factors were selected for further interpretation. The results are displayed in Table 2. The eigenvalue decay 
Table 1. AIPAS descriptive statistics and item analysis results

\begin{tabular}{|c|c|c|c|c|}
\hline \multirow{3}{*}{ No } & \multirow{2}{*}{$\begin{array}{c}\begin{array}{c}\text { Descriptive } \\
\text { statistics }\end{array} \\
(\mathrm{N}=168) \\
\end{array}$} & \multirow{2}{*}{$\begin{array}{c}\text { I-T correlation } \\
\text { analysis } \\
(\mathrm{N}=168)\end{array}$} & \multicolumn{2}{|c|}{ G-P analysis } \\
\hline & & & G-group $(\mathrm{N}=43)$ & P-group $(\mathrm{N}=42)$ \\
\hline & $\mathrm{M} \pm \mathrm{SD}$ & $\mathrm{r}$ & $\mathrm{M} \pm \mathrm{SD}$ & $\mathrm{M} \pm \mathrm{SD}$ \\
\hline 1 & $4.37 \pm 2.04$ & $0.66^{* * *}$ & $6.23 \pm 1.21^{* * *}$ & $2.69 \pm 1.41$ \\
\hline 2 & $4.95 \pm 1.54$ & $0.70 * * *$ & $6.26 \pm 1.11^{* * *}$ & $3.55 \pm 1.35$ \\
\hline 3 & $5.38 \pm 1.60$ & $0.68^{* * *}$ & $6.81 \pm 0.55^{* * *}$ & $4.00 \pm 1.41$ \\
\hline 4 & $5.04 \pm 1.37$ & $0.55^{* * *}$ & $5.79 \pm 1.28^{* * *}$ & $4.00 \pm 1.17$ \\
\hline 5 & $4.60 \pm 1.70$ & $0.68 * * *$ & $6.14 \pm 0.80^{* * *}$ & $3.26 \pm 1.42$ \\
\hline 6 & $5.27 \pm 1.35$ & $0.79 * * *$ & $6.42 \pm 0.66^{* * *}$ & $3.81 \pm 1.19$ \\
\hline 7 & $5.32 \pm 1.36$ & $0.76^{* * *}$ & $6.56 \pm 0.59 * * *$ & $3.93 \pm 0.92$ \\
\hline
\end{tabular}

$* * * \mathrm{p}<0.001$, Item number (No) corresponds to the item shown in Table 2. Values are expressed as mean (M) \pm standard deviation (SD).

Table 2. AIPAS factor analysis results (principal factor method, promax rotation method)

\begin{tabular}{|c|c|c|c|c|}
\hline & \multirow{2}{*}{$\begin{array}{l}\qquad(\mathrm{N}=168) \\
\text { Factors and Items }(\alpha=0.81)\end{array}$} & \multicolumn{2}{|c|}{ Factor loadings } & \multirow[b]{2}{*}{ Communality } \\
\hline & & $F 1$ & $F 2$ & \\
\hline F1 & Self-motivation ( 3 items: $\alpha=0.80$ ) & & & \\
\hline 7 & I understand what I need to do to move forward & 0.95 & -0.06 & 0.84 \\
\hline 6 & It is clear to me what I have to do now & 0.92 & 0.02 & 0.86 \\
\hline 4 & I am clarifying what I can do now and what I cannot do and planning ahead & 0.44 & 0.07 & 0.23 \\
\hline $\mathrm{F} 2$ & Focus on the Present ( 4 items: $\alpha=0.71$ ) & & & \\
\hline $3 *$ & I am still worrying about the past and cannot move forward & -0.03 & 0.71 & 0.48 \\
\hline $1 *$ & I want to run away from my current situation & -0.05 & 0.63 & 0.36 \\
\hline 2 & I have come to terms with the past and am focused on the present & 0.25 & 0.45 & 0.40 \\
\hline \multirow[t]{2}{*}{5} & I do not have any worries and am positively accepting my current situation & 0.22 & 0.44 & 0.36 \\
\hline & Correlation coefficient F1 & - & 0.63 & \\
\hline
\end{tabular}

*Reversing score item

rates were as follows: First factor $=3.41$, Second factor $=1.02$, Third factor $=0.79$. As predicted during the question item gathering process, the first factor was composed of three question items and the question items depicted the current state of the injured athlete as well as predicting the active strategic efforts being conducted for the future. The factor also captured the purposes and degree of goal-directedness of efforts. Taking this into account, the factor was named "Self-motivation." The second factor was composed of four question items which predicted the giving up of the unchangeable reality and the psychological attitude to focus on the present situation. This factor was named "Focus on the Present." The factors named "Self-motivation" and "Focus on the Present" were construed as "Coming to terms with ones emotions" and "Focus on rebuilding life in the future," but the latter factor names did not seem to precisely represent the content of the question items. Therefore the two factor names, "Self-motivation" and "Focus on the Present" were utilized. These identified factors reflect the two injury acceptance concepts initially described and the items composing the same factor, thus proving the factorial validity of the provisional AIPAS.

The Cronbach's $\alpha$ coefficient was calculated to test the scale's reliability. As demonstrated in Table 2, for the over- all scale, $\alpha=0.81$ while for "Self-motivation" $\alpha=0.80$ and for "Focus on the Present" $\alpha=0.71$. The reliability of the whole scale and the subscales is demonstrated by these results. The factor correlation coefficient was $\mathrm{r}=0.63$.

The eigenvalue decay rate of the exploratory factor analysis allows the comparison of one factor or two factor subscales. To compare these two factor analysis models, the goodness of fit between the two models were compared using confirmatory factor analysis. The one factor model produced a goodness of fit of GFI $=0.900$, AGFI $=0.800$, $\mathrm{CFI}=0.901, \mathrm{RMSEA}=0.136$. The two factor model produced a goodness of fit of $\mathrm{GFI}=0.965$, AGFI $=0.925, \mathrm{CFI}=0.982$, RMSEA $=0.060$. The two-factor solution model also displayed a high degree of fit and demonstrates the factorial validity. These results support the results of the exploratory factor analysis.

Table 3 displays the correlation coefficients between the overall and subscale scores of the provisional AIPAS with external criterion indices, Athlete Rehabilitation Dedication Scale (ARDS) overall and subscale scores for participation, completion, and effort. The ARDS and provisional AIPAS had a correlation score of $r=0.40$, with self-motivation $r=0.43$, and with focus on the present $r=0.31$. Each value was significant at the $1 \%$ level. The three compo- 
Table 3. Correlation of AIPAS with external indices to measure criterion-related validity

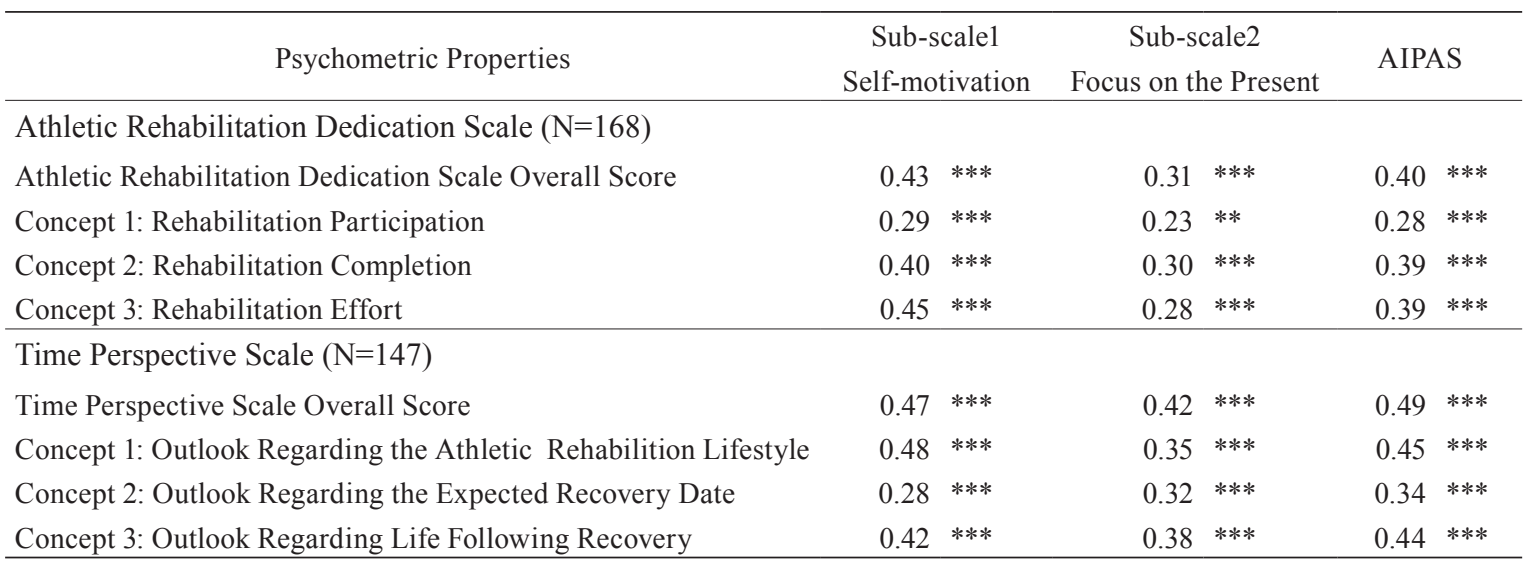

$* * \mathrm{p}<0.01, * * * \mathrm{p}<0.001$

nents of the ARDS, participation, completion, and effort also had a positive correlation with the provisional AIPAS, with correlation values of $r=0.28 \sim 0.39$. The self-motivation subscale positively correlated with ARDS with correlation values of $r=0.29 \sim 0.45$. The focus on the present subscale positively correlated with ARDS with correlation values of $\mathrm{r}=0.23 \sim 0.30$. Each value was significant at the $1 \%$ level. I-T correlation analysis, principal component analysis, and $\alpha$ coefficient analysis were conducted to test whether the overall score of the ARDS could be used as an index to determine the predictive validity of the provisional AIPAS. Each question item had a high correlation with total scores $(r=0.857 \sim 0.901$, all $\mathrm{p}=0.000)$. Similar to the findings of Brewer et al. ${ }^{31)}$, the single dimensionality of the scale (Component loadings $=0.84 \sim 0.90$ ) and the internal consistency of the three question items were fully supported $(\alpha=0.84)$. Taken together, these results indicate that ARDS can be utilized to examine predictive validity. The correlation coefficients between the Time Perspective Scale (TPS) overall and subscale scores (outlook regarding the rehabilitation lifestyle, outlook regarding the expected recovery date, outlook regarding life following recovery) with the provisional AIPAS overall and subscale scores are demonstrated in Table 3. The TPS and the provisional AIPAS had a correlation value of $r=0.49$. The correlation with the subscale of "Self-motivation" was $\mathrm{r}=0.47$ and with "Focus on the Present" was $r=0.42$. Each value was significant at the $1 \%$ level. The correlation value between the subscale of the TPS (outlook regarding the rehabilitation lifestyle, outlook regarding the expected recovery date, outlook regarding life following recovery) with the provisional AIPAS had values of $r=0.34 \sim 0.45$, with the "Self-motivation" subscale $\mathrm{r}=0.28 \sim 0.48$, and with the "Focus on the Present" subscale, $\mathrm{r}=0.32 \sim 0.38$. Each value was significant at the $1 \%$ level. I-T correlation analysis, principal component analysis, and $\alpha$ coefficient analysis were conducted to test whether the overall score of the TPS could be used as an index to determine the predictive validity of the provisional AIPAS. Each question item had a high correlation with total score $(\mathrm{r}=0.823 \sim 0.872$, all $\mathrm{p}=0.000)$. The single dimensionality of the scale (Component loadings $=0.81 \sim 0.89$ ) and the internal consistency of the three question items were fully supported $(\alpha=0.79)$. Taken together, these results indicate that TPS can be utilized to examine predictive validity. The results of the correlation analysis fully support the criterion-related validity of AIPAS.

\section{DISCUSSION}

There is hardly any research concerning a scale that can objectively rate the level of recovery of injured athletes. The purpose of this study was to create the AIPAS, a scale which measures "injury acceptance" among injured athletes. The scale was created using a psychological intervention perspective and using it makes it possible to screen athletes who may be at risk of relatively serious psychological issues.

The concept of injury acceptance which is central to the AIPAS is supported by previous research ${ }^{16-18)}$. Previous quantitative studies by Tatsumi ${ }^{15,19,30)}$ support the validity of creating the AIPAS based on detachment coping theory. The aforementioned studies also support the validity of the use of "Emotionally coming to terms with the injury situation" and "Focusing on rebuilding a new lifestyle" as two factors predicting injury state. For example, Tatsumi ${ }^{15)}$ demonstrated that injured athletes often feel "Why did this happen to me?" or "I was different before my injury," and display signs of anger, regret, self-responsibility, uncertainty and conflict. These emotions make it difficult to emotionally come to terms with the injury and are characteristic responses of injured athletes. The focus of these injured athletes is generally on the past. On the other hand, athletes who are able to accept and come to terms with their injuries are focused on hopes, desires and expectations for the future ${ }^{15)}$, and say things such as "My only choice is to overcome this injury." The framework of the present study was based on previous studies attempting to develop a scale for injury acceptance.

The seven question items that make up the AIPAS were arrived at using a bottom-up procedure based on interviews from previously injured athletes. The question items were carefully reviewed and revised by specialists in the fields of 
clinical and research psychology. The comprehensive procedure for determining the question items resulted in the successful creation of the AIPAS.

No unnecessary items were found from ceiling or floor effects in the aforementioned statistical analysis. Item analysis of I-T correlation analysis and G-P analysis showed that each question could be discriminated from other questions and the result increases the reliability of the scale. Results from exploratory factor analysis identified "Self-motivation" and "Focus on the Present" as two factors of the scale. Confirmatory factor analysis supported this model of analysis. These two factors directly reflect the rating perspective during the question item collection process and also support the results of previous studies ${ }^{15,19,28-30)}$. "Self-motivation" works towards rebuilding lifestyle and predicts how much an injured athlete is involved in coping strategies and is aware of his own state. In the clinical setting, even when the practitioner (doctor, therapist) is providing the best possible medical treatment or training methods, if the injured athlete is not actively involved motivated or involved in the tasks, the treatment and training may not be fully effective ${ }^{15)}$. In contrast, the acquisition of the right mindset can enhance the effects of treatment and rehabilitation. "Focus on the Present" is a state in which the injured athlete realizes that the injury cannot be changed, comes to terms with the injury, and holds a positive attitude. When this state of mind is functioning, it becomes possible for injured athletes to choose between different coping strategies. The scale and subscale is sufficiently reliable and the factorial validity of the factors has been proven through analytical methods.

A significant positive correlation was found between all scale and subscale scores of AIPAS and external indices in the test for criterion-related validity as measured by Pearson's correlation coefficient. These results prove the criterion-related validity of the AIPAS. With regard to "Participation," a subscale of the ARDS, the correlation with injury acceptance was lower compared to the other subscale correlation scores. This result indicates that the effort and motivation of the injured athlete is more important than the actual participation itself. The quality of the rehabilitation seems to be more closely correlated to injury acceptance. Therefore it is of utmost importance to not only focus on the athletes' participation in rehabilitation activities, but to also focus on the quality of the activities that are being conducted. The "Outlook for the Scheduled Return Date" which is a subscale of the TPS demonstrated lower correlation scores with "Self-motivation" and AIPAS overall scores than the other subscales. This result demonstrates that "Outlook for the Scheduled Return Date" is not as predictive of "Selfmotivation" as "Outlook on life after Recovery." Focus on the future seems to enhance the future vision of injured athletes.

The results of the statistical tests fully support the reliability, content validity, factorial validity, and criterionrelated validity of AIPAS. Injury acceptance by injured athletes can be rated by 7 question items, 3 question items regarding "Self-motivation" and 4 question items regarding "Focus on the Present." The small number of question items and the objective rating method will make it easy to use of the scale in a clinical setting.

Future research topics will include testing of construct validity and objective scaling of AIPAS subscales. The type of injury (external, developmental, chronic disorder) involved, stress reaction and stress-coping strategies will provide new perspectives to test the subscales. Rating injuries by ADL and somatic pain and measuring the correlation with injury acceptance will also open further avenues of research.

\section{ACKNOWLEDGEMENT}

This study was financially supported by the research fund of Kio University in 2012.

\section{REFERENCES}

1) Heil JH: Sport psychology, the athlete at risk, and the sports medicine team. In: Psychology of Sport Injury. Champaign: Human Kinetics Publishers, 1993, pp 1-13.

2) Nishimura H: The Art of Control in Sports. Kyoto: Sekaishisosha, 2009.

3) Hughes R, Coakley J: Positive deviance among athletes: the implications of over conformity to the sport ethic. Soc Sp J, 1991, 307-325.

4) Nixon HL: Accepting the risks of pain and injury in sport: mediated cultural influences on playing hurt. Soc Sp J, 1993, 10: 183-196.

5) Nixon HL: A Social network analysis of influences on athletes to play with pain and injuries. J Sport Soc Issues, 1992, 16: 127-135. [CrossRef]

6) Hashimoto K: Life Lost from the Olympics: New Insights 30 Years After Tsuburaya Koukichi. Tokyo: Shogakukan, 1999.

7) Uemukai K: Affective responses and the changes in athletes due to injury. In: Proceedings of the VIII World Congress of Sport Psychology, 1993, pp 500-503.

8) McDonald SA, Hardy CJ: Affective response patterns of the injured athlete: an exploratory analysis. Sp Psycho, 1990, 4: 261-274.

9) Pearson L, Jones G: Emotional effect of sports injuries: implications for physiotherapists. Physiothera, 78, 10: 762-769.

10) Harvey MR, Westen D: Psychometric review of multidimensional trauma recovery and resiliency measures: the MTRRI (interview) and the MTRRQ (sort). In: Measurement of Stress, Trauma, and Adaptation. Lutherville: Sidran Press, 1996.

11) Tedeschi RG, Calhoun LG: The post traumatic growth inventory: measuring the positive legacy of trauma. J Trauma Stress, 1996, 9: 455-471. [Medline] [CrossRef]

12) Petitpas AL, Danish SJ: Caring for injured athletes. In: Sport Psychology Intervention.Champaign, IL: Human Kinetics Publishers, 1995, pp 255281

13) Nakagomi S, Uemukai K: Counseling for athletes who suffered injuries. Jpn J Sp Sci, 1994, 13: 3-8.

14) Tatsumi T, Nokagomi S: A study on psychological acceptance to injury in athletes: analysis from the viewpoint of athletic-rehabilitation behavior. Jpn J Sp Psycho, 1999, 26: 46-57.

15) Tatsumi T: Research on injury-acceptance of athletes: its connection with athletic rehabilitation behavior. Bull Oyasato Inst Reli, 2003, 9: 47-63.

16) Nakagomi S: Sports counseling. In: Sports Psychology: Commonalities between Body, Movement and Mind. Tokyo: Baifukan, pp 241-266.

17) Uemukai K: Psychological problems and solutions for the return from sports injuries. J Health Phy Edu Rec, 2001, 51: 374-378.

18) Uemukai K: Psychological support for sports injuries. In: The World of Sports Psychology. Tokyo: Fukumura Publishing, 2003, pp 226-237.

19) Tatsumi T: Research on injury acceptance among athletes: athletic rehabilitation behaviors based on detachment coping strategies. Bull Nara J Phy Edu Health Sp Sci, 14: 31-38.

20) Grayson M: Concept of acceptance in physical rehabilitation. J Ame Med Asso, 1951, 145, 12: 893

21) Dembo T, Leviton GL, Wright BA: Adjustment to misfortune: a problem of social-psychological rehabilitation. Artif Limbs, 1956, 3: 4-62. [Medline]

22) Wright BA: Physical Disability: A Psychological Approach. New York: Harper \& Row Publisher, 1960, pp106-137.

23) Uemukai K, Takenouchi T: Case study research on sports injury acceptance. Nagoya J Health Phy Fit Sp, 1997, 20: 99-106.

24) Hihara N: Acceptance and Adaptation to Injuries. In: Lesprit Daujourdhui; 
Rehabilitation Psychology. Tokyo: Shibundo, 1996, 394: 73-84.

25) Astle: The experience of loss in athletes. J Sp Med, 26: 279-284

26) Schmale AH, Engel GL: The giving up-given up complex illustrated on film. Arch Gen Psychiatry, 1967, 17: 135-145. [Medline] [CrossRef]

27) Engel GL: A life setting conductive to illness: the giving up-given up complex. Bull Menninger Clin, 1968, 32: 355-365. [Medline]

28) Tatsumi T: Estimating athletes' psychological acceptance to sports injury: developing the coping free of adhesion level scale. J Psycho, 2012, 47 (suppl 1): 370 .

29) Tatsumi T: Psychological acceptance to sports injury in Japanese university elite athletes: coping free of adhesion, perceived physical recovery, and perceived personal growth. J Psycho, 2012, 47 (suppl 1): 370.

30) Tatsumi T: Athletes' psychological acceptance to injury: attitudes to athletic-rehabilitation from the coping free of adhesion. Proceedings of 6th Taipei ASPASP International Congress on Sport Psychology, 2011, 60.

31) Brewer BW, Van Raalte JL, Cornelius AE, et al.: Psychological factors, rehabilitation adherence, and rehabilitation outcome after anterior cruciate ligament reconstruction. Rehabil Psychol, 2000, 45: 20-37. [CrossRef]

32) Fisher AC, Domm MA, Wuest DA: Adherence to sports-injury rehabilitation programs. Phy Sp Med, 1988, 16: 47-52.
33) Duda JL, Smart AE, Tappe MK: Predictor of adherence in the rehabilitation of athletic injuries: an application of personal investment theory. J Sport Exerc Psychol, 1989, 11: 367-381.

34) Lampton CC, Lambert ME, Yost R: The effects of psychological factors in sports medicine rehabilitation adherence. J Sports Med Phys Fitness, 1993 , 33: 292-299. [Medline]

35) Daly JM, Brewer BW, Van Raalte JL, et al.: Cognitive appraisal, emotional adjustment, and adherence to rehabilitation following knee surgery. J Sp Reha, 1995, 4: 23-30.

36) Katsumata T: Concept and structure of time perspective. Bull Kumamoto Univ Mem Edu, 44: 307-318

37) Nurmi JE: How do adolescents see their future?: a review of the development of future orientation and planning. Dev Rev, 1991, 11: 1-59. [CrossRef]

38) Shirai T: Relationships between time perspective and time beliefs from adolescence to middle age. Shinrigaku Kenkyu, 1991, 62: 260-263. [Medline] [CrossRef]

39) Ueno K: Relationship between acquisition of goal-setting skill and time perspective through participation in athletic clubs. Jpn J Phy Edu Health Sp Sci, 2006, 51: 49-60. [CrossRef] 